\title{
Hands to Work: The Practical Artistry of David DeYoung
}

\section{By Lynne Robinson}

Editor's Note: This paper is excerpted from an article that first appeared on the Materials Technology@TMS site. Read the entire article at http://materialstechnology.tms.org/EST/article .aspx?articlelD=2670.

Amid smooth curls of wood and hand tools nearly a century old, things of strength and beauty emerge from David DeYoung's hands. There are favorite projects, "many of them uncompleted," says the immediate past chair of the TMS Aluminum Committee. He has a particular fondness for a clever work organizer that he designed for his wife, Joan, from walnut that he found five miles from his western Pennsylvania home. A pencil post bed awaiting final carving details is also a source of pride.

"I like to use a lot of hand tools the way woodworkers from 150 years ago did," said DeYoung. "It requires a fair bit of thinking and problem solving to make something useful that is also nice to look at."

Although DeYoung traces his initial interest in woodworking to a youth jigsaw his parents gave him one distant Christmas, his hobby took on new life-and meaning-when he discovered it could help him create a comfortable, nurturing environment for his sons, Henry and Andrew, both now in their early 20s. Henry has completed his first year of Ph.D. study in computer science at Carnegie Mellon University (CMU), Pittsburgh, while Andrew is also attending CMU as a chemistry major in his junior year. Both were also diagnosed with spinal muscular atrophy, a progressive muscle-weakening condition, when they were toddlers.

In addition to managing the rigors of Henry and Andrew's academic commitments, much of the day in the DeYoung household revolves around completing daily activities that most take for granted. Both young men

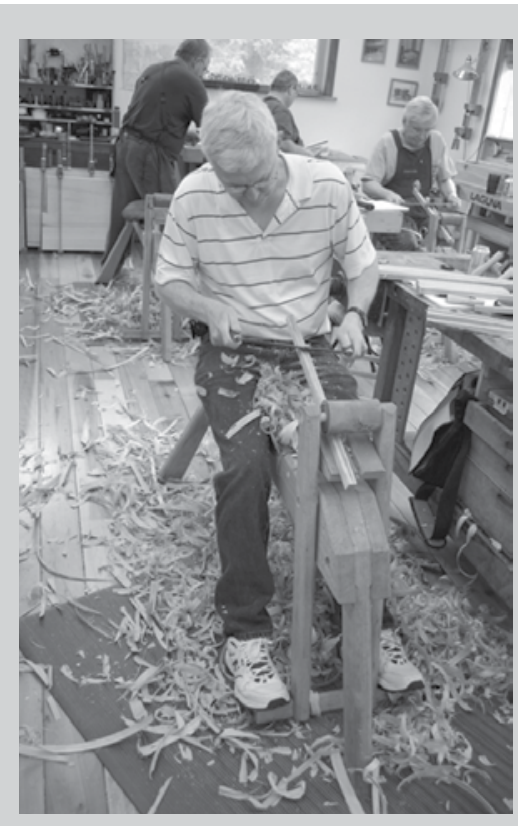

Figure 1. David DeYoung works on a shave horse as he shapes Windsor chair spindles with a drawknife.

depend on motorized wheelchairs for mobility and require a painstaking pulmonary regimen to compensate for their weakened chest muscles. Limited use of their own hands means that they rely on the hands of others for many of their needs, including scribing the mounds of work required of their studies. Their father's hands, in particular, have made it possible for them to enjoy many ordinary pleasures-like looking out a window-that would otherwise have been out of reach.

"After my sons were diagnosed, I realized that there were things that I could make that would really help out - things that I couldn't buy because they really didn't exist," DeYoung said. Over the years, DeYoung has crafted "therapy tables" that enabled him and his wife to work at a comfortable height while caring for their sons. Determining that standard medical equipment cabinets were too awkward for his family's needs, DeYoung made his own. DeYoung's most ambitious project, however, was the one-story house that he designed and had built from scratch to the specific needs of his family.

"I picked a plan out of a book and modified it quite a bit," said DeYoung. "We had been living in a twostory house with our sons and knew at that point what we needed." DeYoung said he also drew on his experiences with his father, who died of amyotrophic lateral sclerosis, or Lou Gehrig's disease, before Henry was born. "I didn't realize it at the time, but seeing what my father needed was a learning experience that prepared me to help my sons," DeYoung said. That's why an important feature of the DeYoung house is windows that are low to the ground, "because people in wheelchairs have a hard time seeing out most windows," he said.

Based on advice given to him by an architect at Children's Hospital of Pittsburgh, DeYoung devised an open floor plan in the living area that has enabled his family to share meals and other everyday experiences comfortably and conveniently. "As the boys have grown, they've not outgrown the house," said DeYoung.

Although family and work-as a technical consultant with the Ingot and Solidification Division at the Alcoa Technical Center in New Kensington, Pennsylvania — are his highest priorities, DeYoung said his woodworking hobby fits as a way to help him gain perspective on the other demands in his life. "It helps me think when I do something with my hands," he said. "Working on a wood project helps me get away from things for a while, so I can start looking at them from a different point."

Lynne Robinson is a writer for Materials Technology@TMS. 